\title{
RECEPCIÓN Y SIGNIFICADO DEL USO CIENTÍFICO DE LA DIALÉCTICA ARISTOTÉLICA
}

\author{
JOSÉ MIGUEL LÓPEZ MOLINA \\ Universidad de Murcia
}

\begin{abstract}
RESUMEN: Este artículo se hace cargo de la recepción y relevancia de la dialéctica aristotélica en el siglo xx. Ésta tiene un uso científico, fundamental en la construcción y desarrollo de la ciencia, que permite, razonando a partir de éndoxa, establecer el valor de verdad de las proposiciones y aprehender los principios comunes de la ciencia así como los principios propios de las ciencias particulares. El procedimiento diaporético teorizado por el Estagirita es método y no conocimiento, a diferencia de Platón, pero hunde sus raíces en la dialéctica platónica del Parménides.
\end{abstract}

PALABRAS CLAVE: dialéctica, epistéme, éndoxa, método, diaporético, aporía.

\section{The Use of Aristotelian Dialectics: Reception and Scientific Meaning}

ABSTRACT: This article shows the relevance of Aristotelian dialectic in the twentieth century, which has a scientific use, basically in the construction and development of science. It allows, reasoning from éndoxa, to establish the value of truth in propositions and to understand the common principles of science and the principles inherent to individual sciences. The diaporétic procedure theorized by Aristotle is a method and not a piece of knowledge, unlike Plato, but rooted in the Platonic dialectic of Parmenides.

KEY WORDS: dialectic, episteme, endoxa, method, diaporétic, puzzle.

\section{LA RECEPCIÓN CRITICA DE LA DIALÉCTICA ARISTOTÉLICA EN EL SIGLO XX}

Uno de los episodios más fecundos en el renacimiento de los estudios aristotélicos del siglo pasado fue el redescubrimiento de una filosofía que ofrecía una teorización sobre una pluralidad de formas y usos de la racionalidad y diversos procedimientos metodológicos acordes con problemas entonces en boga, como la racionalidad de discursos no científicos o problemas de procedimiento y método de la ciencia.

Sobresale, sin duda, la argumentación dialéctica como método en la investigación científica y la construcción de las ciencias. La dialéctica y sus relaciones con la ciencia y la filosofía (primera), su papel como método en la investigación científica y como forma de racionalidad tematizada por el Estagirita, ha sido uno de los tópicos en la crítica aristotélica de la segunda parte del siglo xx, hasta tal punto que no solo se ha reconocido el valor de la dialéctica en su filosofía, sino que ha dado un sentido nuevo a toda ella ${ }^{1}$.

En efecto, Aristóteles se consideró a sí mismo como el primero en llevar a cabo una teorización completa sobre el razonamiento (logismós), esto es, tanto del razonamiento apodíctico como dialéctico. Esto no significaba que no hubiesen sido utilizados con

1 «[... si darebbe un senso nuovo all'intera filosofia de Aristotele, recuperando da un lato el suo stetto legame con quella platonica e metendo in luce dall'altro il suo rapporto con la filosfia moderna e contemporanea» p. 124, y « mettendo in luce il carattere problemático ed al tempo stesso necesario» p. 133, E. Berti: «La dialettica in Aristotele», en: Sutdi aristotelici, L'Aquila, Japadre Editore, 1975, p. 124 y p. 133, publicado origianalmente en L'attualità della problemática aristotelica, Atti del Convegno francoitaliano su Aristotele (Padova, 6-8 aprile 1967), Padova, Editrice Antenore, 1972, pp. 33-80. 
anterioridad sino que Aristóteles fue el primero en llevar a cabo una reflexión sistemática sobre las formas de racionalidad o, si se quiere, una teoría general de la racionalidad. Así lo afirma en Refutaciones sofisticas: "En cuanto a este estudio, en cambio, no es que una parte estuviera elaborada y otra no, sino que no había nada en absoluto» ${ }^{2}$, y también más adelante, en la conclusión: «Sobre las cuestiones de retórica existían ya muchos y antiguos escritos, mientras que sobre el razonar no teníamos absolutamente nada anterior que citar, sino que hemos debido afanarnos empleando mucho tiempo en investigar con gran esfuerzo» ${ }^{3}$. Estas afirmaciones se refieren al conjunto TópicosRefutaciones Sofísticas, pues éstas no son más que su noveno libro, pero probablemente pueda hacerse extensible al conjunto Analíticos-Tópicos ${ }^{4}$. El estudio de la argumentación dialéctica, realizado en Tópicos, conforma con el estudio del silogismo en general en Primeros analíticos y el por el silogismo científico (apodíctico) en Analíticos posteriores, una reflexión sobre las tipologías del razonamiento. Los elementos de éstos, los términos o conceptos y las proposiciones o juicios, son estudiados en Categorías y Sobre la interpretación, completando el denominado posteriormente Organon, probablemente así llamado por Alejandro de Afrodísia.

En gran medida, la recepción completa de Aristóteles en este asunto ha sido posible gracias a los Symposia Aristotelica, convocados, en su origen, por I. Düring y G. E. L. Owen. Sobre todo, a partir del segundo, celebrado en Lovaina en 1960 —el primero fue celebrado en Oxford en 1957- dedicado a "Aristóteles y los problemas del método»" El siguiente, versó precisamente sobre Los Tópicos, «Aristotle On Dialectic: The Topics», Oxford 1963. Aunque el siguiente Symposium no trató estos temas ${ }^{6}$, se celebró un congreso franco-italiano al año siguiente, 1967, en Padova, profundizando en el valor de la dialéctica en la filosofía aristotélica. Puede decirse que estos encuentros permitieron la recuperación de la dialéctica aristotélica y marcaron la crítica de las décadas posteriores. Hasta entonces había dominado una concepción reduccionista sobre la teoría y la metodología de la ciencia aristotélica, considerando el silogismo deductivo, como única y exclusiva forma de racionalidad científica y método propio de ésta. Esta interpretación, dominante en la Modernidad, se configuró partir del juicio negativo dictado por Roger Bacon sobre la metodología de la ciencia aristotélica y la cierta ineficacia del método silogístico-deductivo para el progreso de la ciencia, y a partir del juicio de Kant sobre la dialéctica cómo «lógica de la apariencia» ${ }^{7}$, en virtud de la naturaleza probable de las premisas del silogismo dialéctico y su desconocimiento, por lo demás, de la obra del Estagirita. Frente a la ciencia (apodíctica), verdadero conocimiento, la dialéctica

2 Aristóteles: De Sophisticis Elenchis 34, 183 b 34-36. Trad. Miguel Candel: Madrid, Gredos, 1982.

3 Soph. elen. 34, 184 a 8-b 2.

4 Cf. Berti, E., Las razones de Aristóteles, Buenos Aires, Oinós, 2008, p. 36.

5 Mansion, S., Aristote et les problèmes de méthode, Louvain, Intitut supérieur de philosophie, 1961.

6 Düring, I. (Ed.), Naturphilosophie bei Aristoteles und Theophrast, Heidelberg, Lothar Stiehm Verlag, 1969. Verhandlungen des $4^{\circ}$ Symposium Aristotelicum veranstaltet in Göteborg, August, 1966.

7 Las críticas de Bacon se enmarca en la polémica entre vetus organum y novum organum y por ende, en los desarrollos de la construcción de la llamada ciencia moderna. Cf. García MARQuÉs, A., "Aristóteles: la construcción de la epistéme», en: A. Sierra González, Y. Romero Morales (eds.): Razón, crisis y utopía, Tenerife, Universidad de la Laguna, 2011. No obstante, también aristotélicos de la época como J. Zabarella reducían el Órganon a Analíticos. Incluso grandes lectores de Aristóteles como Hegel minusvaloran la lógica aristotélica, cf. BerTI, E., Las razones..., pp. 15-16. Por lo que respecta a Kant, cf. por ejemplo KrV A 61 / B 86: «Por muy diferente que haya sido la acepción en que los antiguos tomaron la ciencia o el arte de la dialéctica, se puede colegir, partiendo de la forma en que efectivamente la empleaban, que no significaba para ellos sino la lógica de la apariencia. Se trataba de un arte sofístico para dar apariencia de verdad a la ignorancia...», cito por trad. esp. RiBAs, P., Crítica a la razón pura, Madrid, Alfaguara, 1988 (18 ed.), p. 99. 
aparecía como mera opinión o probabilidad, y por tanto, sería denostada como un procedimiento cuasi sofístico. Los grandes especialistas aristotélicos posteriores como Zeller, Hamelin y Robin ${ }^{8}$ se mantuvieron en posiciones más o menos parecidas. Tan solo en las décadas anteriores a la celebración de segundo Symposium hubo estudios que fueron variando las posiciones tradicionales, como los trabajos de Regis, Blond, Weil, Viano y Lugarini ${ }^{9}$, pero no tuvieron repercusión histórica suficiente. Destaca el estudio de Le Blond que fue desautorizado por A. Mansion, a la sazón autoridad internacional en los estudios aristotélicos ${ }^{10}$.

Las contribuciones de Aubenque, Sur la notion aristotécienne d'aporie ${ }^{11}$, y Owens, Tithénai ta Phainómena, que a la postre se convirtieron clásicos de la crítica aristotélica, mostraron que en «Aristóteles hay mucho más que cuestiones de mera lógica formal: el Estagirita habría teorizado una pluralidad de usos de la razón conducentes a establecer la verdad en muy diversos ámbitos y con muy diverso alcance ${ }^{12}$, y, en palabras de Berti, «prácticamente se rehabilitó la tesis de Le Blond y se descubrió la cantidad innumerable de métodos teorizados y practicados por Aristóteles» ${ }^{13}$.

A partir de esa década, la pluralidad de métodos y formas de racionalidad teorizadas por Aristóteles multiplicaron los trabajos de los especialistas sobre la dialéctica y su significado y relación con la elaboración de su filosofía. Así, por ejemplo, encontramos importantes contribuciones de L. Sichirollo, la edición y estudio de crítico de Tópicos realizada por Brunschwig ${ }^{14}$, o los trabajos de Couloubaritsis, que dirigiría la edición de un notable número de la Revue Internationale de Philosophie sobre la metodología de Aristóteles ${ }^{15}$. Multitud autores ahondaron en la noción de dialéctica, su papel en la construcción de la ciencia y su relación con la metafísica como Lezl, Evans, Irwin y Barnes ${ }^{16}$.

8 Zeller, E., Die Philosphie der Griechen, II, 2, Leipzig, 1923, pp. 242-245; O. Hamelin: Le système d'Aristoteles, Paris, 1920, p. 229; RoBin, L., Aristotle, Paris, 1944, pp. 41-44.

9 Berti sostiene que esta corriente de autores de «interpretazione benevola» sobre la dialéctica (la dialéctica tendría un valor intermedio entre la ciencia y la sofística además de cierta utilidad para las ciencias), coincide en lo esencial con la interpretación tradicional por cuanto solo juzgaría a la dialéctica desde el punto de vista cognoscitivo o científico. Cf. Berti, E., «La dialettica...», pp. 117-119. Por lo demás, tendría su origen en Тнurot, C., Estudes sur Aristote: Politique, dialectique, rhétorique, Paris, 1860, pp. 132-134, y que, además de los arriba citados, se han de citar a RegIs, M., L'opinion selon Aristote, París, 1935; Le Blond, J. M., Logique et methode selon Aristote, París, Vrin, 1939; Wiel, E., «La place de la logique dans la pensée aristotèlicienne», en: Revue de Metaphisique et de morale, 1951, pp. 283-315; Wieland, W., Das Problem der Prinzipienforschung und die aristotelische Physik, Kant-Studien, 52, 1960-61, 206-19; Lugarini, L., "Dialettica e filosofia in Aristotele», en: Il Pensiero 4, 1959, pp. 48-69, y, Aristotele e l'idea della filosofia, Firenze, La Nouva Italia, 1961; Viano, C. A., «La dialettica in Aristotele», en Vari: Studi sulla dialettica, Torino, 1958; Moreau, J., Aristote e son école, Paris, 1962, o De Pater, W. A., Les Topiques d'Aristote et la dialectique platonicienne, Fribourg, 1965. Cf. asimismo, Aguirre, J., «Dialéctica, diaporía y saber positivo», en: Éndoxa: Series Filosóficas, n 26, Madrid, UNED, 2010, pp. 11-41, para visión sintética del elenco bibliográfico en las décadas siguientes.

10 Mansion, A., Introduction à la physique aristotélicienne, Paris, Vrin, 1945.

${ }_{11}$ Cit. trad. esp., Aubenque, P., "Sobre la noción aristotélica de aporía», en: Lecturas sobre Platón y Aristóteles I, Buenos Aires, OPFyL, 2000, pp. 89-100.

12 García Marqués, A., "Aristóteles...», p. 295.

13 Berti, E., Las razones..., p. 18.

14 Schirollo, L., Giustificazzioni della dialettica in Aristotele, Urbino, 1963; Storicità della dialettica antica, Padova, 1965, y, La dialettica, Milano, 1973; Brunschwig, J., Topiques I-IV, Paris, Les belles lettres, 1968.

15 Couloubaritsis, L., «Dialectique et philosophie chez Aristote», en: Philosophia VIII-IX, 1978-79, pp. 229-256, y, la edición monográfica sobre «La méthodologie d'Aristote», en: Revue Internationale de Philosophie, vol. 34, números 133-134, Bruselas, 1980.

16 Leszl, W., Logic and methaphysic in Aristotle, Padua, 1970, y Aristotle's conception of ontology, Padua, 1975; Evans, J. D .G., Aristotle's conception of dialectic, Cambridge, 1977; IRWIN, T. H., «Aristotle's 
Pero, sobre todo, destacan las figuras de Berti y Aubenque que marcaron las posiciones fundamentales sobre Aristóteles, y agruparon en torno a ellos a numerosos discípulos ${ }^{17}$. En el congreso de Padua, que no Symposium Aritotelicum, ambos presentaron sus ponencias ${ }^{18}$ sobre la dialéctica, en línea con sus trabajos anteriores ${ }^{19}$. Para Aubenque, la imposibilidad de acceder científicamente, i.e. apodícticamente, al objeto de la metafísica, limita su propio alcance y la hace coincidir de hecho con la dialéctica ${ }^{20}$. Berti, por su parte, defendió el uso científico (filosófico) de la dialéctica parar el conocimiento de los principios de la ciencia y la verdad o falsedad de las proposiciones. Filosofía y dialéctica no se identificarían pues no serían lo mismo, la primera sería un saber teórico-científico, la segunda, poiético-metodológico, pero esto no implicaría que ésta no pudiera ser instrumento de aquélla. Además de la labor crítica, la dialéctica no estaría huérfana de valor demostrativo, pues la confutación sería un tipo de ésta.

Sin embargo, la fecundidad de Aristóteles sobrepasó los círculos de especialistas y se constituyó en matriz filosófica para multitud de pensadores y desarrollos intelectuales de la segunda parte del siglo xx. Por citar algunos, C. Perelman y su teoría de la argumentación, conocida como la «nueva retórica», sostuvo a partir de Aristóteles, formas discursivas no sujetas a formalización, i.e. las propias del mundo humano: ética, política y jurídica; la Escuela de Chicago, considerados «neoaristotélicos» ${ }^{21} \operatorname{como} \mathrm{R}$.

discovery of Metaphysics», en: The review of Metaphysics XXXI, 1976-77, pp. 210-29; BARNEs, J., "Aristotle's theory of demostration», en: Articles on Aristotele, Cambridge, 1975, pp. 65-87.

17 Berti, E., Nuovi studi aristotelivi I, Brescia, Morcelliana, 2004; Dialectique, physique et métaphysique. Éstudes sur Aristote, Lovaina, Peeters, 2008; Rossito, C., Studi sulla dialettica in Aristotele, Nápoles, Bibliopolis 2000; Aubenoue, P., Problèmes aristotèliciens, 1, París, Peeters, 2009.

18 Berti, E., «La dialettica...»; Aubenque, P., «La dialectique chez Aristote», en: L'attualità..., pp. 9-31.

19 Aubenoue, P., Le probleme e l'être chez. Aristotete, París, 1962 (cit. por trad. esp.: El problema del ser en Aristóteles, Madrid, Taurus, 1974). BerTi, E., L'unitá del sapere in Aristotele, Padua, CEDAM, 1965. Puede, por tanto, decirse que las tesis del autor francés no se ven modificadas por las investigaciones de estos años. "El hombre, en cierto sentido, está condenado a pensar el ser dialécticamente» (p. 473), esto es, la imposibilidad de conocer los primeros principios y la totalidad del ser en cuanto ser impide la constitución de una ciencia primera. La fuerza de la teoría de la ciencia (apodíctica) sigue centrifugando otras formas de racionalidad con fuerza cognoscitiva.

${ }_{20}$ No serían lo mismo, señala, pero «si la recherche et la tentative sont l'affaire de la dialectique, alors la science de l'être en tant qu'être est dialectique...», en AubEnque, P., "La dialectique chez Aristote», en: L'attualità...p. 29. Señala Aguirre, resumiendo la posición de Aubenque, que «dialéctica y metafísica se identifican en su limitación, es decir, en la imposibilidad de ambas por llegar al establecimiento de verdades mediante demostración», en «Dialéctica, diaporía y saber positivo», en: Éndoxa..., p. 15.

21 La llamada Escuela de Chicago, los Críticos de Chicago o Neoaristotélicos de Chicago, son una escuela americana de crítica literaria que «desde distintos ámbitos de las humanidades, coinciden en el replanteamiento de las funciones de estas disciplinas, en especial a los relativos a los educación», cf. el gran trabajo de García Rodríguez, J., Neoaristotélicos de Chicago, Madrid, Arco Libros, 2000, p. 14. Aunque exceden el ámbito filosófico, destaca por ejemplo, la centralidad del concepto aristotélico de mímesis como fundamento de toda practica crítico-literaria, la Poética y sus categorías como texto fundamental de la tarea crítica, etc. El texto pistoletazo de salida de la Escuela es de R.S. Crane: «History versus criticism in the University Study of Literature», 1935. En puridad podrían haberse llamado la «nueva crítica» pues el texto J. C. Ransom The New Criticism que, como es sabido dio nombre a esta corriente, es de 1941. Kennet Burke por lo demás, fue el primero en nombrar el trabajo de la Escuela como neoarisotélico en The Philosophy of Literary Form, Louisiana, Baton Rouge, State University Press, 1941.

Sin embargo el concepto "neoaristotelísmo» es complejo y su extensión diversa. Su uso a veces se limita a autores del contexto americano pertenecientes a ese primer momento de filósofos alemanes emigrados a los EE.UU como Strauss, L., Voegelin, E., Arend, H. y sus escuelas, que en general, se ocuparon de filosofía de la praxis, pero más comúnmente, integra al segundo momento «teórico-sistemático» en el que participaron distintas escuelas alemanas no estrictamente filosóficas. Cf. VolPI, F., «Rehabilitación de la filosofía practica y neo-aristotelismo», en: Anuario Filosófico, 32, Navarra, 1999, pp. 315-342, para una visión panorámica de las ideas, autores y escuelas implicados. 
S. Crane, R. Mckeon, E. Olson; Gadamer y sus discípulos basaron la hermenéutica en la prudencia como paradigma del saber práctico. La denominada «rehabilitación de la filosofía práctica» ${ }^{22}$ con autores como R. Bubner, W. Hennis, G. Bien o J. Ritter, tiene a Aristóteles como autor de cabecera.

También, en la denominada nueva epistemología (Bachelard, Popper, Kuhn, Watkins, Prigogine y otros ${ }^{23}$ ) se encuentra una revalorización del Estagirita. En el caso de Feyerabend, por ejemplo, se encuentra una progresiva valoración y apropiación de elementos aristotélicos ${ }^{24}$, aunque con interpretaciones heterodoxas. También ocurre finalmente, en autores posmodernos como Derrida y Lyotard ${ }^{25}$.

En consecuencia, puede decirse que la tematización de los distintos modos de proceder de la razón humana llevada a cabo por Aristóteles ha permitido no solo una relectura del propio autor sino que ha tenido un gran ascendente sobre el pensamiento de las últimas décadas.

\section{2. El uso CIENTífico dE LA DiALÉCTICA: El MÉTOdo DiAPORÉTICO}

\section{a) De la ciencia}

A partir del concepto de ciencia establecido en Analitica posteriora se puede mostrar cómo la dialéctica se relaciona con la ciencia. Aquélla ocupa un lugar irremplazable respecto a ésta, pues ni todo se puede establecer demostrativamente ni todo se puede aprehender directamente, es decir, la facultad de conocer se halla mediada por sus procedimientos.

Aristóteles establece que ciencia, en sentido estricto, es episteme apodeiktiké, esto es, ciencia apodíctica, demostrativa, deductiva. En Ética Eudemia, ciencia es definida como "hábito demostrativo» ${ }^{26}$ (hexis apodeiktiké); en An. post. establece que el silogismo científico es el silogismo demostrativo: «a la demostración la llamo razonamiento científico ${ }^{27}$. Aunque ciencia es definida como demostración, no toda ciencia es apodíctica, hay ciencia no demostrativa (epistéme anapódeiktikos) como ahora veremos.

22 Cf. Volpi, F., «La rinascita della filosofia pratica in Germania», en: Pacchiani, C. (ed.): Filosofía pratica e scienza politica, Abano-Padova, 1980, pp. 11-97 para una visión sintética de este debate. No obstante, el primer texto compilatorio, ya clásico, fue M. Riedel (ed.): Rehabilitier der praktischen Philosophie, 2 vols., Freibug, 19721974.

${ }_{23}$ Cf. el estudio de Berti, E., Arsitotele nel Novecento, Bari, Laterza, 2008 (1 ${ }^{\text {a }}$ ed. 1992) pp. 246-260.

24 Se advierte una progresiva presencia del Estagirita en sus escritos, más allá de Eine Lanze für Aristoteles (1980). Como botón de muestra, recuérdese, por ejemplo, lo que él denomina principio aristotélico: «las necesidades de una forma concreta de vida determinan qué se considerará real» en: La conquista de la abundancia, Barcelona, Paidós, 2001, p. 293, a propósito de la critica que el Estagirita le hace al Bien platónico en la Ética a Nicómaco (1096 b 3-1097 a 13); Feyerabend piensa que Aristóteles hace dos tipos de críticas, una en el que hace gala de «criticismo lógico» (imposibilidad que existan en un Bien en sí), otra, en atención a los resultados de esas tesis: la ineficacia de ese Bien para adquirirlo y realizarlo por el hombre; Aristóteles, a este respecto, dice: «y lo que buscamos ahora es algo de esa naturaleza». Otro ejemplo más curioso, es la aparición de un ensayo póstumo con el título Aristóteles, incluido en La conquista de la abundancia, que desconcertó a Bert Terpstra; dice Feyerabend: «De cualquier modo que enfoquemos una determinada materia podemos aprender mucho de Aristóteles respecto a conocimiento, la investigación y las implicaciones sociales de ambos» p. 261.

25 Cf. Berti, E., Las razones..., pp. 19-20.

26 EE, VI 3, 72 b 18-20. Trad. J. Pallí Bonet, Madrid, Gredos, 1985.

27 An. Po. I 271 b 18-19. Trad. M. Candel SanMartín, Madrid, Gredos, 1988. 
Poseemos ciencia sobre algo ${ }^{28}$, i.e. un estado de cosas, una sustancia, una propiedad, un comportamiento, cuando conocemos las causas por las que un objeto considerado es de un determinado modo y no de otro, es decir, conocemos las causas que constituyen necesariamente determinada realidad. Poseer, pues, un conocimiento científico es conocer el que es y ante todo, el porqué es de cualquier realidad. La necesidad se entiende como una relación, es decir, no se trata de que determinado estado de cosas posea por sí necesidad, sino de que dados determinados efectos, o mejor, dados determinados estados de cosas, han de darse necesariamente sus razones, sus condiciones, sus causas.

La ciencia apodíctica, por tanto, es un conocimiento por causas necesarias que acontece en relaciones determinadas entre juicios, esto es, en razonamientos, silogismos; no en todos, en los científicos. Un silogismo es un razonamiento en el que asumidas al menos dos premisas, una mayor y otra menor, se sigue algo distinto, la conclusión. Ésta mantiene con aquellas una dependencia de necesidad y causalidad. Las premisas o juicios se relacionan en virtud de los tres términos que las componen; extremos de la proposición o juicio se denominan a los que se unen o separan en la conclusión, siendo el mayor el predicado en la conclusión y el menor el sujeto. El tercer término se denomina medio y establece el nexo de unión con los otros dos; es contenido por uno de los otros y contiene al que no le contiene. En el silogismo científico las premisas deben poseer unas características: "verdaderas, primeras, inmediatas, más conocidas, anteriores y causas de la conclusión ${ }^{29}$. Inmediatas y primeras, significa que las premisas no pueden remitir a ulteriores demostraciones —entonces, no serían primeras-, deben ser indemostrables o derivar de tales, pues una demostración continua de premisas impide precisamente la ciencia. Más conocidas, por su parte, significa bien "para nosotros», esto es, emparentadas con la sensación y, por tanto, premisas particulares, bien «por naturaleza», esto es, universales. Estas últimas son el sentido propio y autentico, modelo, de la ciencia aristotélica, donde la conclusión está causada necesariamente por las premisas universales.

Las premisas que cumplen estas características se les llama "principios propios» de la ciencia, no de toda o de todas, sino de una determinada, es decir, son los principios necesarios que constituyen una ciencia determinada. Éstos son de dos tipos: definiciones y presupuestos (hypótesis). Los primeros establecen el qué es o la esencia. Los segundos, presuponen si algo es, i.e. existe, bien sea un objeto, un predicado o una relación entre ambos. Por tanto, a partir de los «principios propios» se deducen, se demuestran, propiedades con las características arriba citadas, esto es, propiedades causadas universal y necesariamente. Sin embargo, también, hay otros principios generales, esto es, no específicos de una ciencia, denominados axiomas; éstos son necesarios para el conocimiento de cualquier ciencia o grupo de ciencias. Se trata de los «principios comunes». No son principios a partir de los cuales se deduzca nada, sino de principios operativos en el discurso racional. Entre los principios constitutivos de la racionalidad se cuentan el principio de no contradicción y el principio de tercero excluido. Entre los "principios comunes» constitutivos de algún grupo de ciencias se cuenta, por ejemplo, «sustrayendo iguales de iguales se obtienen iguales», axioma común de las ciencias matemáticas y sus aplicaciones (óptica, armónica, astronomía...).

28 «Creemos que sabemos cada cosa sin más, pero no del modo sofístico, accidental, cuando creemos conocer la causa por la que es la cosa, que es la causa de aquella cosa y que no cabe que sea de otra manera", An. po. I 2, 71 b 9-12.

29 An. Po. I 2, 71 b 21-22. 
En suma, cada ciencia necesita de unos "principio propios», indemostrables por sí misma, que la configuran como tal, es decir, determinan su género, y por tanto, la especifican respecto a otras, y además, unos "principios comunes» operativos en el propio discurso racional. En consecuencia, la demostratividad de cada ciencia queda determinada por sus «principios propios» que no pueden ser demostrados ni por sí misma ni por otra ciencia, ni puede, a su vez, demostrar los principios de otra ciencia. En consecuencia, en virtud de ellos, digámoslo una vez más, se encuentra determinada al género de objetos definidos y presupuestos. Las ciencias demostrativas son, en consecuencia, siempre particulares. Buscar una ciencia universal capaz de demostrar los principios comunes a todas las ciencias y los principios propios de cada una de las ciencias ha sido desde siempre pretensión de filósofos y escuelas ${ }^{30}$. De hecho, ha sido una postura dominante desde la Academia platónica hasta el Racionalismo, mas para Aristóteles no es posible. Por una parte, hablar de demostración significa hablar de un género de objetos determinado por unos principios propios y no es posible transitar de un género a otro ${ }^{31}$. De modo que hay una irreductibilidad entre las ciencias particulares. Por otra, si los principios propios de una ciencia fuesen demostrables por una supuesta ciencia universal demostrativa de principios propios, la noción misma de principio entraría en contradicción; los principios propios de cada ciencia ni serían primeros ni indemostrables, ni por tanto principios. Además, la supuesta ciencia universal, en tanto que demostrativa -posee sus propios principios y género de objetos- no puede demostrar sus propios principios, con lo que no sería universal ni primera; el género de objetos, por lo demás, no podría constituirse debido a su irreductibilidad.

Por lo demás, Berti ha subrayado en diversos estudios ${ }^{32}$ que la ciencia concreta a partir de la cual, Aristóteles teoriza este concepto de ciencia es la geometría - conocida más tarde como euclidiana-, y ésta constituida en objeto de enseñanza, es decir, ya configurada en corpus doctrinal y no en grado de tentativa o desarrollo. Aristóteles piensa, pues, en el científico que posee una ciencia y la enseña, la demuestra, a partir de premisas (definiciones y asunciones) ante alguien que no sabe, en un proceso, por lo demás, esencialmente monológico. La demostración, por tanto, comportaría un marcado carácter pedagógico ${ }^{33}$.

La naturaleza de los principios nos sitúa en límite de esta racionalidad científica, demostrativa, y abre el espacio a otro tipo de ciencia no demostrativa, la epistéme anapódeiktikos, «no toda ciencia es demostrativa — dice Aristóteles-, sino que la de las cosas

30 A juicio de Berti, la comprensión de la metafísica como ciencia universal está presente en comentadores del Estagirita tanto en la Antigüedad tardía y el Medievo, entre los que se pueden contar a Temistio, Filopón, Averroes, Alberto Magno, Tomás de Aquino y Egidio Romano, como en la Modernidad. Destaca J. Zabarella de quién tomó Descartes el ideal de la metafísica como raíz del árbol de la ciencias. Cf. Berti, E.: «Metafisica e dialettica nel Commento di Giacomo Zabarella agli Analitici posteriori», en: VV AA: Giornale di metafisica, 14, 1992, pp. 225-244, y E. Berti: Las razones..., p. 28, n. 2.

31 An. po. I 7, 75 b 8-14.

32 «[...] el modelo de esta ciencia [la teorizada en An. post.] es la geometría, la primera ciencia descubierta por los griegos y, a la vez, la única que había alcanzado, en tiempos de Aristóteles, lo que hoy llamaríamos un estatuto epistemológico casi definitivo», p. 29. Ciencia que Aristóteles «encontraba frente a sí ya realizada, que él, por su parte, no practicó y de ningún modo contribuyó a desarrollar»; Euclides, en fin, no hizo otra cosa más que «sistematizar una geometría que ya existía en tiempos de Aristóteles», cf. Berti, E., Las razones..., pp. 29-30. Cf. asimismo Berti, E., «L'analisi geometrica della tradicione euclidea e l'analitica di Aristotele», en: Giannantoni, G., y Vegetti, M., La scienza ellenistica, Napoli, Bibliopolis, 1984, pp. 93-128.

33 A este respecto cf. BARNES, J., "Aristotle's Theory of Demostration», en: J. Barnes, M. Schofield y R. Sorabji (eds.): Articles on Aristotle, vol. I, London, 1975, pp. 69-73. Cit. Berti, E., Las razones..., p. 29. 
inmediatas es indemostrable» ${ }^{34}$. Esta ciencia de lo no demostrable la llama Aristóteles «principio de la ciencia» y se ocupa, pues, de los principios, i.e. axiomas, presuposiciones y definiciones. En puridad no es ciencia, si por esta se considera ciencia apodíctica; es ciencia en sentido amplio. El Estagirita la llama nous, inteligencia, intelección. Se trata de un conocimiento no discursivo sino intuitivo. En An. post. la presenta como resultado de una epagogé, esto es, de una intuición, pero no en el sentido de una intuición intelectual, i.e. sin mediación de la sensibilidad, ni de una percepción inmediata, sino como aprehensión de los principios, i.e. las definiciones, a través de un proceso en el que el alumno —recuérdese el carácter didáctico de la apodíctica- es llevado hasta la captación de los conceptos. En Met. IX 10, 1951 b 17-1952 a 2, señala que las esencias se aprehenden o no, pero sobre los principios, i.e. las esencias, los conceptos, no cabe engañarse, es decir, el nous capta o no las esencia, si no lo hace continua en su ignorancia, si lo hace, se aprehende en su verdad, pero en ningún caso se está en el error respecto a ellas. Indica, además, que sobre los principios hay una investigación. Esto no entra en contradicción con lo dicho anteriormente, sino que subraya el otro aspecto, el de la construcción de la ciencia.

Nótese, por tanto, los dos momentos en los que acontece la intelección de los principios; por una parte, el que ilustrado en una ciencia aprehende sus "principios propios», y por otra, aquel que ha construido esa ciencia, que ciertamente sus principios le son conocidos no discursivamente pero tampoco inmediatamente, esto es, son fruto de una ardua investigación. La importancia, pues, de la situación concreta en la que acontece el conocimiento de los principios queda establecida por la distinción metódica entre via inveniendi y via docendi ${ }^{35}$.

En metafísica, el nous se ocupa de establecer los principios de un objeto muy particular, el ente en cuanto ente, y no de esencias particulares, propias de las ciencias particulares. El nous mantiene así una íntima relación con esta ciencia primera, pues se puede decir que la constituye desde dentro. Así lo indica Aristóteles por ejemplo en Met. VI 11025 b 14-15, y VII 17, 1041 b 9-11. Recuérdese aquí, además, EE VI, 1141 a 16-10: en la Sabiduría concurren nous y ciencia, pues conoce los principios del objeto universal y su ciencia.

Pues bien, ante el concepto de ciencia apodíctica y anapodíctica de An. post. se presentan interrogantes sobre el proceder mismo de la ciencia. La demostración rinde siempre y cuando tengamos las definiciones, i.e. las esencias, los conceptos. Éstas se establecen a través del nous, bien sea por una buena práctica docente en el caso propio de la ciencia apodíctica, bien sea a través de un proceso arduo de investigación, decíamos anteriormente. Ahora bien, ¿cómo se procede en tal proceso para estar en condiciones de aprehender los principios? La construcción de la ciencia, apenas tratada, es precisamente el espacio que ocupa la dialéctica, no toda ella, solo la discusión, el diálogo, que tenga como fin la ciencia.

34 An. po. I 3, 72 b 19-20.

35 A juicio de Marqués: "Aristóteles no está hablando de dos ciencias, sino de dos momentos o aspectos o procesos que se dan en toda ciencia. [...] epagogé y (nous) y apódexis son los dos procesos básicos que recorre la mente humana en la compresión de la realidad». En apoyo de esta tesis subraya que ha habido en la tradición una continuidad en la tematización de tales procesos, análisis y síntesis, inventio et iudicium, resolutio et compositio, tópica y crítica, inducción y deducción, etc.; por no hablar simplemente de todos los desarrollos que han subrayado la intuición como aprehensión de los principios: intuicionismo intelectualistas, bergsoniano, husserliano, volitivos, etc. Cf. García MARqués, A., "Aristóteles...», p. 300. 


\section{b) De la dialéctica}

Aristóteles aborda en Tópicos el estudio de la dialéctica como procedimiento racional, i.e., riguroso, seguro, controlado, para tratar cualquier problema propuesto a partir de premisas reputadas:

El propósito de este estudio es encontrar un método (méthodos) a partir del cual podamos razonar sobre todo problema que se nos proponga, a partir de éndoxa, y gracias al cual, si nosotros mismos sostenemos un enunciado, no digamos nada que le sea contrario ${ }^{36}$.

Aristóteles busca, pues, reglar y teorizar el procedimiento, el método, de la dialéctica (dialégesthai), es decir del diálogo, no en el mero sentido de platicar o conversar, sino en el de discutir sobre cualquier problema propuesto. Este diálogo pues, se sirve del razonamiento, i.e. la argumentación (logismós), como instrumento para su objeto, un problema, que debe, además, presentarse de un modo determinado. A partir de las proposiciones, configuradas según el propio, la definición, el género o el accidente, se forman los problemas en una interrogativa que implique una respuesta afirmativa o negativa, es decir, una contradicción (antífasis); por ejemplo, animal pedestre bípedo ies la definición de hombre o no? ${ }^{37}$

Aristóteles se ocupa de clarificar en qué consiste y cómo se forma un problema dialéctico. No todo problema (ni toda tesis), advierte, se ha de considerar como problema, solo aquellos que necesiten una clarificación argumentativa, no una corrección (kólasis) o adecuada sensación ${ }^{38}$. Se consideran como problemas, cuestiones (theoréma) «tendentes al deseo y al rechazo, bien a la verdad y el conocimiento» (Tóp., I 11, 104 b 2-3), ya sean, en fin, consideradas por sí mismos o como medio para otros asuntos. También son problemas, cuestiones de las que hay «argumentaciones contrarias» (Ib., b 13) y las que «Son muy amplias» y no «tenemos argumentos» (Ib., b 12-13). Además, determinadas cuestiones se convierten en tesis dialécticas ${ }^{39}$, i.e. juicios paradójicos, de autores "conocidos en el terreno de la filosofía» (Ib., b 19-20), o cuestiones de las que tenemos «algún argumento contrario a las opiniones habituales» (b 24-24).

Se trata pues, de establecer las condiciones racionales de la discusión. Si señalábamos que Aristóteles pensaba en la geometría en An. post., aquí nuestro autor tiene como referencia la práctica pública de la discusión tan extendida en el mundo griego. Las deliberaciones políticas en las asambleas o las disputas judiciales en los tribunales sobre

36 Top. I 1, 100 a 18-21. CANDEL, M. traduce Éndoxa por «plausibles», cf. n. 3, pp. 89-90. Brunschwig sostiene una interpretación de éndoxa como «ideas admitidas» por individuos o colectividades; éndoxa apuntaría a una aceptación subjetiva de las proposiciones en cuestión más que a su propio valor de verdad. T. Irwin en: «Ways to fist principles: Aristotle's methods of discovery», en: Philosophical Topics 15, 2, 1987 109-42 (cit. por Lloyd p. Gerson: Aristotle Critical Assements, London/Usa, Routledge, 1999. pp. 4950 n. 16) se inclina por traducir por «opiniones comunes reputadas», en contra de J. Barnes ( Aristoteles and the method of ethics», en: Revue Internationale de philosophie 34, 1981, 490-511) "dignas de estima». Arguye que endoxon es tratado como equivalente e phainomenon, dokoun o legomenon. También, Berti prefiere traducir directamente por «reputadas», pues la diferencia entre "premisas verdaderas» y éndoxa no es una diferencia de grado que parece sugerir "premisas probables», como si la cercanía a la verdad se pudiese medir en términos estadísticos, ni es una diferencia entre verdaderas y aparentes, como sugiere la traducción "premisas verosímiles» en contra de J.M. Le Blond: Logique et methode..., cf. también Las razones... pp. 41-42.

37 Cf. Top. I 4, 101 b 11-35.

38 Top. I 12, 105 a 3-5.

39 La distinción entre tesis y problema no es definitiva. «De todos modos, actualmente todos los problemas dialécticos viene a llamarse tesis. Se les llame como se les lame, no se diferencian en nada» Top. I 11, 104 b 34-105 a 1. 
cualquier asunto configuraban el habitual discurrir de la pólis griega. Se trataba, ante todo, de mantener la propia tesis y desacreditar la opuesta ante un público siempre presente. Naturalmente, este desacreditar podía hacerse dialécticamente o erísticamente.

El alcance de la dialéctica es irrestricto, universal, no limitándose a ningún ámbito concreto como las ciencias particulares. El problema puede abordar aspectos determinados, pero en virtud de tal universalidad se busca, ante todo, preguntarse por la esencia, el concepto. Se pregunta sobre las premisas y se articulan razonamientos buscando la contradicción (élenchos), la refutación o apórema. Se siguen en todo momento, las reglas de la argumentación ya teorizadas en An. post. Los fines de la interrogación pueden ser diversos, como enseguida veremos, aunque fundamentalmente dos, dialéctico y cognoscitivo.

Lo específico del razonamiento dialéctico reside en la naturaleza de sus premisas, los éndoxa. Si no se respeta esto, si los que dialogan no comparten las premisas, entonces no hay diálogo ninguno. Razonar a partir de éndoxa es lo específico de la dialéctica; en ellos se cifra el alcance y los límites de la dialéctica. Escuchemos al propio Aristóteles al respecto:

Hay demostración cuando el silogismo parte de premisas verdaderas y primeras, o cosas cuyo conocimiento se origina a través de premisas primordiales y verdaderas; en cambio, es dialéctico el razonamiento construido a partir de premisas reputadas (éndoxa). Ahora bien, son verdaderas y primordiales las cosas que tienen credibilidad, no por otras, sino por sí mismas (en efecto, en los principios cognoscitivos no hay que inquirir el porqué, sino que cada principio ha de ser digno de crédito en sí mismo); en cambio, son éndoxa aquellas que son compartidas (ta dokoúnta) por todos o por la mayoría o por los sabios, y entre éstos, por todos o por la mayoría o por los más conocidos y reputados (éndoxi) ${ }^{40}$.

La diferencia, pues, entre ambos silogismos se encuentra en sus premisas, las primeras son verdaderas y admitidas por sí mismo, las segundas, las dialécticas, son admitidas por la mayoría o por los sabios ${ }^{41}$. No dice más, es decir, no dice ni que sean verdaderas ni falsas. La razón de ello se encuentra en que la dialéctica no trata de la verdad o falsedad sino de la discusión ${ }^{42}$, busca la contradicción del interlocutor; para ello es necesario el común acuerdo sobre las premisas. La gran extensión que afirma Aristóteles, al decir por todos o por la mayoría o por los sabios, se entiende fácilmente porque se está refiriendo al uso de la dialéctica sobre cualquier asunto y contexto. Ciertamente éndoxa es un adjetivo formado a partir de doxa, opinión. Por tanto, significaría opiniones, premisas opinadas, pero no opiniones cualesquiera sino opiniones de la mayoría o de los sabios, y entre éstos, no todos, según, todos o la mayoría o los más conocidos y reputados. Nótese, que Aristóteles utiliza éndoxi para caracterizar a los sabios con más fama, gloria. Esto confirma, a juicio de Berti, que el uso de éndoxa tiene el sentido de reputado, famoso, de modo que la traducción correcta debe ser

40 Top. I 1, 100 a 25-100 b 23.

${ }^{41}$ Los éndoxa, premisas del razonamiento dialéctico, son (Tóp. I 10, 104 a 7-15): 1) «una pregunta plausible, bien para todos, bien para la mayoría, bien para los sabios, y entre éstos, bien para todos, bien para la mayoría, bien para los más conocidos, y que no sea paradójica: pues cualquiera haría suyo lo que es, siempre que no sea contario a las opiniones de la mayoría»; 2) «las semejantes a las plausibles, 3) las contrarias a las plausibles, propuestas en forma de contradictoria, y 4) «todas las opiniones que están de acuerdo con las técnicas conocidas».

42 «La proposición demostrativa difiere de la dialéctica en que la demostrativa es la asunción de una de las dos partes de la contradicción (pues el que demuestra no pregunta, sino que asume), en cambio la dialéctica es la pregunta respecto de la contradicción» An pr. I 1, 24 a 22-25. 
"premisas reputadas» ${ }^{43}$. Los éndoxa son, pues, las opiniones de los especialistas, de los que pueden opinar, las opiniones autorizadas ${ }^{44}$.

La naturaleza de las premisas también distingue el silogismo dialéctico del silogismo erístico o sofisma ${ }^{45}$. Esta vez, en base a la distinción entre los éndoxa auténticos y aparentes. Se trata de razonamientos que asumen los éndoxa aparentes, falsos, cuya intención no es más que la pura disputa. No se trata de equívocos o errores — si así fuera se denomina paralogismo- sino de engaños, de falsificaciones. La diferenciación entre realidad y apariencia confirma, además, que Aristóteles considera a los éndoxa en el silogismo dialéctico, como hemos señalado, como opiniones verdaderas. Junto a razonamientos que toman sus premisas de los éndoxa, la formación de problemas según los cuatro predicables, y el proceso dialógico de preguntas y respuestas en busca de una contradicción, Aristóteles establece los instrumentos de la dialéctica y los «lugares» (Topói) de la discusión. En cuanto a lo primero, señala ${ }^{46}$ :

Los instrumentos a través de los cuales llevaremos a buen término los razonamientos son cuatro: primero, tomar las proposiciones; segundo, poder distinguir de cuántas maneras se dice cada cosa; tercero, encontrar las diferencias; cuarto, la observación de lo semejante.

Nótese la importancia de estos instrumentos en proceder dialógico. Son los asertos para comenzar el examen de las tesis. Destaca, sin duda, el segundo, pues es la llave de la determinación del objeto de la metafísica: los sentidos de ser. Nótese, además, que la gran parte de los Top., II-VII, se ocupan de teorizar precisamente los «lugares», esto es, los esquemas de la argumentación, formados por la combinación de los predicados, esenciales o no y coextensivos o no $^{47}$.

Por lo demás, la delimitación entre tipos de silogismos y cómo se establecen las diferencias entre filosofía (ciencia), dialéctica y erística ocupa gran lugar en las disquisiciones de Aristóteles. Sobresalen las distintas clasificaciones que realiza sobre los silogismos: al apodíctico lo llama filosoféma; al dialéctico epicheiréma, al dialéctico que concluye en una contradicción (élenchos) —o sea, un tipo particular_lo llama apórema;

43 Cf. Berti, E., Las razones..., p. 42, y n. 36 del presente artículo. El valor de verdad de los éndoxa ha suscitado debates sobre la base epistemológica del procedimiento dialéctico, i.e. cómo desde opiniones se establece la verdad y la falsedad y los principios de la ciencia, cf. Bolton, R., «The epistemological basis of aristotelian dialectic», pp. 57-106, en: SIM, M., en From puzzles to priciples?, Boston, Lexington Books, 1999, (publicado por primera vez: Devereux, D., Pellegrin, P., (eds.): Biologie, Loguique et Métaphysique chez Aristote, Paris, Éditions du Centre National de la Recherche Scientifique, 1990, pp. 246-286). BERTI, E., «L'uso scientifico della dialettica in Aristotele», en: E. Berti: Nuovi studi aristotelici, Brescia, Morcelliana, 2004, pp. 265-282, siguiendo a FAIT, P., «Argomentazione e comparazioni endosalli: sulla struttura del metodo dialettico aristotélico", in: Annali del Dipartamento di Filosofia, Universidàt de Firenze, 7 (1991), pp.7-14, sostiene una interpretación coherentista de la dialéctica: no es el grado de los éndoxa, i.e. la cantidad y la cualidad, sino la coherencia con la mayor parte de ellos, signo suficiente de su verdad para Aristóteles.

44 En uso de éndoxa en sentido de reputadas, autorizadas, es confirmado en otras obras como por ejemplo $E E:$ «[...] es inútil examinar todas las opiniones que algunos tienen sobre la felicidad. Muchas ideas, efecto, se forjan los niños, los enfermos y los locos, sobre los que ningún hombre sensato se plantearían problemas... Hemos de examinar solamente las opiniones de los sabios...» cf. EE I 8, 1214 b $29-1214$ a 5 .

45 Top. I 1, 100 b 26-101 a 4.

46 Top. I 13, 105 a 22-25. Para el primero, cf. I 14, 105 a 35-105 b 40; para el segundo, 15, 106 a-107 b 37; para el tercero, 16, 107 b 38-108 a 6; para el cuarto, 17, 108 a 7-17. Para resumen y utilidad, 18, 108 a $18-108$ b 35.

47 Cf. Candel, M., «Introducción», en: Tópicos, Madrid, Gredos, pp. 85-86. 
y, al erístico lo llama sofisma ${ }^{48}$. En Ref. sof. establece tipologías según distintos criterios como por ejemplo según el tipo de refutación, real o aparente, muy importante para distinguir una verdadera refutación de una falsa refutación, i.e. sofística, o en fin, clasificaciones generales, i.e. los tipos de razonamientos en los discursos son: didascálicos, dialecticos, periásticos y erísticos ${ }^{49}$. Destaca la introducción de periástica (péira, examinar) como un tipo de razonamiento dialéctico caracterizado por examinar las opiniones de aquellos que dicen que saben con fin de buscar alguna contradicción con sus premisas. Este fue el proceder de Sócrates, de modo que Aristóteles, podría decirse, lo establece como categoría, aunque, como se observa, es similar al apórema. No obstante, en Ref. sof. está subrayando la intencionalidad de los distintos argumentos, en este caso, la utilidad crítica.

\section{c) Del uso científico de la dialéctica}

Una vez establecida una delimitación conceptual suficiente, es necesario abordar los distintos usos de este método para notar la importancia de su uso en las ciencias filosóficas. Así lo introduce Aristóteles ${ }^{50}$ :

Se podría decir para cuantas y cuales cosas es útil este estudio. Y lo es para tres cosas: para ejercitarse (pros gymnasían), para las conversaciones (pros tas entéuxeis) y para las ciencias filosóficas (pros tas katá philosophían epistémes).

Es decir, la dialéctica se utiliza en tres ámbitos, en el técnico, esto es, la simple y llana adquisición de una técnica, que una vez dominada produce distintos beneficios en sus empleos; en la praxis, esto es, en la vida pública donde es necesario dirimir discursivamente multitud de asuntos; y en la teoría, esto es, útil para el conocimiento científico.

Respecto al uso pros gymnasían a de decirse que «resulta claro por las cosas mismas», esto es, en tanto que técnica de la discusión a de ejercitarse, entrenarse y aprenderse. Aristóteles la juzga como una disciplina, un arte que, por tanto, hay que aprender a utilizar eficazmente. Ejercitarse para conocer bien esta disciplina es la diferencia entre el que participa sin arte (atéchnos) y el dialéctico ${ }^{51}$, «teniendo un método — señala-, podremos habérnosla más fácilmente con lo que nos sea propuesto».

Respecto al uso pros tas entéuxeis:

Porque habiendo inventariado las opiniones de la mayoría, discutiremos con ellos no a partir de convicciones ajenas, sino a partir de las suyas propias, forzándoles a modificar aquello que nos parezca que no dicen bien ${ }^{52}$.

Se trata, pues del uso público, modelo para Aristóteles y uso más habitual, en el que lo buscado prevalecer bien en la defensa de una tesis, bien en la negación de ella.

Respecto al uso pros tas katá philosophían epistémes dice Aristóteles ${ }^{53}$ :

[Es útil] para las ciencias filosóficas (philosophían epistémes) porque, si somos capaces de desarrollar las dificultades (diaporésai) en ambas direcciones, discerniremos más fácilmente en cada una lo verdadero y lo falso. Además, es útil para las cosas primeras de cada ciencia. En efecto, a partir de los principios propios de la ciencia en cuestión es imposible decir algo sobre ellos, puesto que los principios son primeros

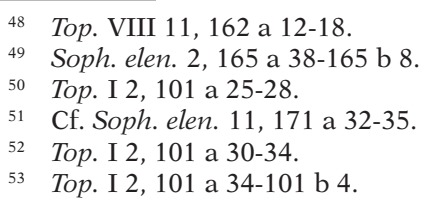

53 Top. I 2, 101 a 34-101 b 4. 
entre todas las proposiciones, y por ello es necesario proceder respecto a ellos a través de éndoxa. Ahora bien, esto es propio o exclusivo de la dialéctica; en efecto, siendo ella inquisitiva (exetastiké) posee el camino hacia los principios de todos los tratamientos científicos.

De entrada debe señalarse que la expresión philosophían epistémes no se refiere a un tipo particular de ciencia sino a la ciencia misma, a la ciencia en general. Para Aristóteles epistéme y philosophía poseen la misma extensión semántica, siendo utilizadas como sinónimos ${ }^{54}$. Además, la distinción de filosofía "primera» siempre juega el papel de separar la nueva ciencia de las demás ${ }^{55}$.

Por tanto, Aristóteles señala que la dialéctica tiene otro empleo, además de los citados, cuyo fin es el conocimiento científico. Nótese, lo que Aristóteles está afirmando. A pesar de que la dialéctica no puede demostrar, pues no tiene un objeto determinado ni unos principios propios - lo constitutivo de cualquier ciencia- y solo cuenta con los llamados principios comunes, los cuales no son premisas demostrativas, puede ser utilizada con una intención cognoscitiva. En concreto, para el avance de la ciencia, distinguiendo tesis verdaderas y falsas y en la investigación de sus principios.

Aunque normalmente este uso de la dialéctica se le conoce como el tercero, los comentaristas han discutido si en realidad no se trata de cuatro usos, es decir, habrían dividido este tercer uso en dos según las dos funciones que el mismo Aristóteles atribuye a la dialéctica en este punto. Brunschwig ${ }^{56}$ en su famosa edición de los Tópicos, sostiene que la primea parte sería una prolongación de la dialéctica platónica, y la segunda, referente al conocimiento de los principios, sería fruto de un Aristóteles maduro que ya ha desarrollado la teoría de la ciencia de Analíticos. Esta tesis se apoya además en la presunta separación entre «ciencias filosóficas» y la totalidad de la ciencia, donde la tercera utilidad se aplicaría a las primeras y la cuarta a la segunda. Devereux ${ }^{57}$, por el contrario, sostiene que en la primera parte no se trata de argumentos propiamente dialécticos, y que la segunda pertenece a versiones de los Tópicos antiguas sujetas a fuerte influencia platónica. Smith ${ }^{58}$, por su parte, sostiene que la primera parte se encuentra referida a la elaboración de la teoría científica y la segunda, referida a los principios comunes.

Berti ha sostenido ${ }^{59}$ la unidad de la tercera utilidad en base a tres argumentos. En primer lugar, no está demostrada la redacción sucesiva del texto. En segundo lugar, «ciencias de carácter filosófico» significa la ciencia propiamente dicha, es decir, ciencia y filosofía son sinónimas, como ya indicamos más arriba. Y, en tercer lugar, y como argumento decisivo, Berti sostiene que la unidad de tal uso está justificada por la estrecha conexión entre la naturaleza periástica, examinativa ${ }^{60}$, de la dialéctica, que permite conocer los principios (cuarta utilidad) y el recorrer la aporía para discernir lo verdadero y lo falso (tercera utilidad). Las tesis candidatas a constituirse como principios se establecen del mismo modo en que se resuelven las aporías: estableciendo una tesis y su contraria y buscando la confutación de una de ellas a través de las ulteriores

54 Cf. Met., VI 1, 1026 a 18-21: «Por consiguiente, habrá tres filosofías especulativas: la matemática, la física y la teológica».

55 Cf. Berti, E., «L'uso scientifico della dialettica in Aristotele», p. 266.

56 Brunschwig, J., Topiques, p. XII y n. 4 p. 116.

57 Devereux, D., "Comments on Robert Bolton's. The epistemological Basis of Aristotelian Dialectic», en: Devereux, D., Pellegrin, P., (eds.): Biologie, Loguique et Métaphysique chez Aristote, Paris, Éditions du Centre National de la Recherche Scientifique, 1990, pp. 246-286.

58 Sмітн, R., "Aristotle on the Uses of Dialectic», en: Synthèse 96 (1993), pp. 335-357.

59 Berti, E., "L’uso scientifico... », pp. 267.

60 En la $E E$, Aristóteles utiliza «recorrer las aporías» (diaporésai) (I 3, 1214 a 2) como sinónimo de «examinar las opiniones» (exetastiké) (I 3, 1215 a 6-7). 
deducciones que se contradigan. La confutación de una tesis equivale a la demostración de la otra. Por tanto, es inseparable esa supuesta cuarta utilidad de la tercera ya que constituye su mismo proceso.

En consecuencia, esta utilidad está referida a la ciencia y consta de dos dimensiones: distinguir más fácilmente lo verdadero de lo falso, y conocer los principios de la ciencia. Respecto al primer aspecto, por lo tanto, señala Aristóteles que la dialéctica es un método, una técnica, que puede tener como fin el conocimiento científico. En segundo lugar, señala cómo es posible conseguir este fin: a través de aporías. No en su mera formulación, sino en su desarrollo: «desarrollar las dificultades en ambas direcciones» (pros amphótera diaporésai) para discernir fácilmente en cada una lo verdadero de lo falso, es decir, señala en qué consiste ese «recorrer la aporía»: deducir de cada una de las tesis de la aporía hasta encontrar una consecuencia contradictoria que refute tal o cual tesis. De este modo, sabremos «más fácilmente» cual tesis o elementos de ella son verdaderos y cuales falsos. Ciertamente, esta es una descripción básica del proceso. Normalmente, el mismo Aristóteles no rechaza de plano una tesis y acoge otra sin más, sino que recoge elementos de una tesis bajo determinadas consideraciones y rechaza otros según otras. La relevancia de este instrumento es confirmada en Tóp. VIII 14, 163 b 9-11:

En relación con el conocimiento y con la inteligencia filosófica el poder abarcar con una mirada de conjunto las consecuencias que derivan de cada una de las dos hipótesis es instrumento no menor.

Tras la introducción del método diaporético y sus características, se refiere a la noción de aporía. Primero introducida en un sentido psicológico (Tóp. VI 145 b 3) después producida por una dificultad teórica (Tóp. VIII 145 b 19-20):

La incertidumbre (aporía) es una igualdad de razonamientos contrarios (isostés enantión logismós).

La igualdad de razonamientos contrarios parece ser productora de la incertidumbre (aporía).

La noción de aporía se encuentra integrada en la diaporética como uso científico de la dialéctica, y no al revés, es decir, la diaporética desarrollada a partir de la aporía. Sin embargo, en tanto que el proceder dialéctico se especifica a partir de la formulación de aporías, este instrumento metodológico adquiere mayor relevancia en el corpus y la representación misma del proceder dialéctico.

\section{d) La fuerza de la nueva dialéctica}

El trasfondo teórico que subyace en la concepción de la dialéctica como instrumento (organon) de la filosofía con valor cognoscitivo es la dialéctica platónica. Aunque, como es sabido, con una diferencia esencial, para Platón la dialéctica constituye la ciencia misma y no un instrumento de ella. Pero no es la diferencia lo que hay que destacar en estos pasajes sino su estrecha dependencia, pues el uso que sostiene Aristóteles —en este primer aspecto- es el mismo que Platón en el Parménides refiere a la práctica inaugurada por Zenón ${ }^{61}$ :

[...] Esfuérzate y ejercítate más, a través de esa práctica aparentemente inútil y a la que la gente llama vana charlatanería, mientras aun eres joven. De lo contrario, la verdad se te escapará. ¿Y cuál es el modo de ejercitarme, Parménides? Ese —respondióque escuchaste de los labios de Zenón.

61 Parménides 135 d - e. Cf. Berti, E., "Zenone di Elea inventore della dialettica?», en: Berti, E., Nuovi studi aristotelici, pp. 353-370, para un estudio minucioso de esta cuestión. 
Es más, de la invitación de Parménides a Sócrates para que utilice el ejercicio de Zenón, se infiere que, tal y como práctica su dialéctica (periástica) Sócrates, era insuficiente para argumentar sobre la teoría de la Ideas. Más aun, Platón por boca de Parménides desarrolla esta práctica —ilustrada en el Parménides a través de un ficticio diálogo entre el viejo Parménides y un jovencísimo Aristóteles (no el Estagirita, sino uno de los futuros Treinta tiranos)- incluyendo la deducción de los contrarios, esto es, del mismo modo en que Aristóteles ${ }^{62}$ señala como diaporésai: para distinguir lo verdadero de lo falso es necesario deducir de las dos ramas del problema hasta encontrar una confutación.

Esta ampliación en la dialéctica, hasta entonces no practicada por Sócrates, es a la que se refiere Aristóteles en Met. XIII 1078 b 23-27:

Sócrates buscaba justamente la qué-es, puesto que buscaba razonar silogísticamente, y principio de los silogismos [científicos] es el qué-es; en aquel tiempo, en efecto, la fuerza dialéctica (dialektiké ischýs) no era aún tanta como para poder indagar los opuestos, incluso prescindiendo del qué-es, y si es [es decir, en qué casos] la misma la ciencia de los contrarios.

Es decir, a partir del Parménides, al menos, existe una dialéctica con mayor capacidad para conocer la verdad a través de la «indagación de los opuestos», esto es, a través de la verdad o falsedad de las consecuencias deducidas de los distintos miembros de la aporía. En el texto, además está operativa la teoría de la ciencia aristotélica que vimos anteriormente. Para razonar científicamente es necesario conocer las esencias, i.e. principios propios: definiciones. Ahora bien, esta nueva dialéctica permite razonar «incluso prescindiendo del qué-es». Permite, pues, conocer con verdad aun sin conocer las definiciones. Aristóteles, por tanto, no hace otra cosa que asumir esta dialéctica platónica del Parménides en este uso epistemológico de la dialéctica que ilustramos.

Respecto a la segunda dimensión del uso filosófico de la dialéctica Aristóteles es claro: los principios de las ciencias particulares no pueden demostrarse, precisamente porque son primeros; de modo que han de ser establecidos dialécticamente, esto es, a partir del examen de los éndoxa. Ésta constituye, pues, lo específico de la dialéctica en virtud de su naturaleza inquisitiva (exetastiké), es decir, en virtud de su naturaleza examinativa (peirastiké). La dialéctica es método, poiésis, técnica, al servicio del conocimiento, en este caso del nous, capacidad para aprehender los principios como ya señalamos. El procedimiento es el mismo que en la primera dimensión: el examen de los éndoxa a partir del establecimiento aporías. En el caso de los principios, la formación de problemas debe ser radical, esto es, enfrentar opiniones contradictorias y no meramente contrarias.

62 «Me parece, en efecto — dijo [Sócrates]—, que de ese modo no hay dificultad en mostrar que las cosas que son son tanto semejantes cuanto desemejantes y que están afectadas por cualquier otra posiciones». A lo que añade Parménides: «Muy bien; pero, además de eso, debemos hacer esto otro: no solo suponer que cada cosa es y examinar las consecuencias que se desprenden de esa hipótesis, sino también suponer que esa misma cosa no es, si quieres tener mayor entrenamiento». Ante la nueva pregunta de Sócrates, Parménides explicita el procedimiento: «Por ejemplo, si tú quieres, a propósito de la hipótesis que propuso Zenón, «si hay multiplicidad», examinar qué debe seguirse para los múltiples mismos, tanto respecto de sí mismos como respecto de lo uno y para lo uno, tanto respecto de sí mismo como respecto de los múltiples. Y, a su vez, poniendo como hipótesis "si no hay multiplicidad», examinar nuevamente qué ha de seguirse...». Par. 135 e -136a-b. La cursiva es mía. La tesis según la cual Aristóteles hace suya la nueva dialéctica del Parménides, y que es, en definitiva, la que llamamos diaporética es sostenida por grandes especialista, cf. DürIng, I., Aristóteles, Mexico, UNAM, 1990, p. 95; BERTI, E. :«Aristote et la méthode dialectique du Parmenide de Platón», en: Revue Internationale de Philosophie, 1980 (34), pp. 341-358; Zadro, A., Aristotele, Topici, Napoli, Lofredo, 1974, p. 541; ZanatA, M., "Dialéctica y ciencia en Aristóteles», en: AA VV: Anuario Filosófico (35), 2002, pp. 25-52. 
Ahora bien, puede señalarse una especificidad en esta dimensión de la dialéctica que resalta, si cabe, su valor. Aristóteles señala que el procedimiento diaporético en la primera dimensión permite «discernir más fácilmente en cada una [de las ramas de la aporía] lo verdadero y lo falso», es decir, cabría no hacerlo de este modo sino normalmente o difícilmente, esto es, tal y como procede la ciencia: deductivamente a partir de premisas primeras u otras ya demostradas.

Sin embargo, al enfrentarse al conocimiento de los principios no se poseen premisas de ningún tipo, excepto naturalmente, las comunes. Su alcance es "propio o exclusivo» de la mediación del procedimiento dialéctico: el establecimiento de aporías a partir de los éndoxa. Puede, por tanto, reconocérselo como terreno genuino de la dialéctica.

En consecuencia, el uso científico de la dialéctica se configura como la contraposición de tesis enfrentadas. Recibe, entonces, el nombre de aporía; su desarrollo, esto es, la deducción de consecuencias hasta hallar contradicciones lo ha llamado diaporésai, por eso, este modo de buscar, de hallar conocimiento, se le llama procedimiento o método diaporético. En tanto que el propio Aristóteles utiliza el nombre de apórema para nombrar al tipo de silogismo dialéctico que termina en una contradicción, y para nombrar a los «problemas» ya establecidos, también se le llama procedimiento aporemático o diaporemático. La diferencia, grosso modo, entre aporía y diaporético reside en que la primera se refiere bien a la situación de perplejidad o dificultad causada por «una igualdad de razonamientos contrarios», bien al problema ya formulado para su resolución, y el segundo a su desarrollo; éste supone el segundo sentido de aporía y un sentido metodológico. Ciertamente, hay matices importantes, como han mostrado los estudiosos, pero en la práctica suelen ser utilizados como sinónimos.

Aristóteles ha dicho al comienzo de Tópicos que busca «un método (méthodos) a partir del cual podamos razonar sobre todo problema que se nos proponga a partir de cosas reputadas (éndoxa)», por tanto, no es de extrañar que lo encontremos en toda la obra del Estagirita: los ámbitos de la praxis, ética y política, la filosofía de la naturaleza, y por supuesto, en la filosofía primera. Sin embargo, destaca por encima de todo ésta última, sobre todo el libro Beta de la Metafísica porque constituye el texto donde mayor desarrollo encuentra el método diaporético: menciona y describe explícitamente el método, profundizando además en las semántica del porós: aporésai, diaporésai y euporésai, y establece una serie de aporías según tales reglas, dando comienzo a la propia investigación metafísica.

Universidad de Murcia

José Miguel LóPez Molina

Josemiguel.lopez@um.es

[Artículo aprobado para publicación en diciembre de 2014]. 


\title{
LA CIENCIA EN EL FINAL DE LA EDAD MEDIA
}

IGNACIO VERDÚ BERGANZA

Universidad Pontificia Comillas.

\begin{abstract}
RESUMEN: El presente artículo pretende mostrar que, en el ámbito de la ciencia, la Edad Media no fue un período oscuro y sin avances significativos, y que la modernidad no supuso una ruptura con lo hecho al final del medievo, sino algo muy distinto. Decir lo contrario es mantener un tópico que desfigura la realidad.

PALABRAS CLAVE: Aristóteles, innovación, Grosseteste, ruptura, Bradwardine, aritmética, algebra, Merton College, Trigonometría, Oresme, Física, Buridán, impetus, Ockham.
\end{abstract}

\section{The science at the end of the Middle Ages}

ABSTRACT: TThis article aims to show that, in what concerns science, the Middle Ages were far from obscure and marked by lack scientific progress. The event of modernity did not entail a break with science at the end of the Middle Ages, but something very diferent. To keep on asserting the existence of a break represents reiterating without any real foundations.

KEY WORDS: Aristotle, innovation, Grosseteste, rupture, Bradwardine, arithmetic, algebra, Merton College, trigonometry, Oresme, Physics, Buridan, ímpetus, Ockham.

Abordar en un artículo como éste un asunto tan complejo como el de cuál era el estado de la ciencia, sus logros y progresos, al final de la Edad Media, así como la influencia que éstos pudieron ejercer en lo que conocemos como la modernidad, es una tarea nada fácil, pero, sin duda, estimulante.

Entre el siglo XIII y el xIV se produjeron extraordinarios avances, cambios, progresos, rupturas, desarrollos, polémicas y descubrimientos en todos los ámbitos de la cultura. Esto se constata en la Política, la Teología, la Lógica, la Metafísica, el Arte (arquitectura, escultura, pintura, literatura, música) y, como no, en la Ciencia (Filosofía de la Naturaleza).

Hasta tal punto es esto así que no pocos estudiosos del periodo han situado en éste el final de la Edad Media y el comienzo de una nueva era; la de Petrarca o Gioto, la del comienzo de la matematización de la naturaleza y la secularización-laicización del mundo ${ }^{1}$.

En efecto, la cuestión de la continuidad o no entre lo hecho en el medievo y la modernidad, naturalmente también en el ámbito científico, es ineludible, y ha sido la base de una disputa, en ocasiones enconada, entre ciertos medievalistas y estudiosos dedicados a los inicios de la Edad Moderna.

Como es bien sabido, a lo largo del siglo xvir se extendió la idea, ya avanzada desde el humanismo, de que la Edad Media había sido un triste período de estancamiento, si no de retroceso, para la humanidad. Francis Bacon, por poner un ejemplo, en su Novum Organum, afirmaba que las edades transcurridas entre la antigüedad y la suya propia habían sido desfavorables para las ciencias, "pues ni los árabes ni los escolásticos

1 De Lagarde, G., Le naissance de l'esprit la que au déclin du Moyen Âge, Louvain, E. Nauwelaerts, $1956-1970$ 